\title{
Solução nutritiva e composição mineral de três espécies de menta cultivadas no sistema hidropônico
}

\author{
Nutrient solution and mineral composition of three mint species grown in hydroponic system
}

\author{
Tânea Maria Bisognin Garlet ${ }^{\mathrm{I}^{*}}$ Osmar Souza dos Santos $^{\mathrm{II}}$
}

\section{RESUMO}

O objetivo do estudo foi determinar o teor $e$ a acumulação de nutrientes em três espécies de Mentha e testar o desempenho de solução nutritiva calculada para o cultivo de menta, a partir de dados anteriores de produção de matéria seca e de quantidade de nutrientes extraídos por M. arvensis, no sistema hidropônico NFT Técnica do Fluxo Laminar de Nutrientes (NFT). O trabalho foi conduzido em casa de vegetação de $250 \mathrm{~m}^{2}$ do Departamento de Fitotecnia da UFSM, RS, Brasil, no período de outubro a dezembro de 2004. Empregou-se delineamento experimental inteiramente casualizado, com três tratamentos (órgãos da planta) e cinco repetições. Estacas de plantas matrizes foram enraizadas em espuma fenólica por 20 dias em berçário e após foram transferidas para bancadas de produção final. As plantas foram colhidas aos 62 (M. arvensis), 69 (M. x gracilis) e 76 (M. x piperita var. citrata) dias após o plantio, separadas em partes (raízes, hastes, folhas) e secas em estufa a $70^{\circ} \mathrm{C}$ para determinação de matéria seca e análise de tecidos. Nitrogênio, cálcio e potássio foram os macronutrientes com maior concentração em todas as partes das plantas, já os micronutrientes foram ferro, manganês e zinco. Houve maior acúmulo de macronutrientes nas folhas, seguidas pelas hastes $e$ raízes. Constatou-se que a solução nutritiva elaborada garantiu elevada produção de fitomassa, sem que as plantas apresentassem sintomas visuais de deficiência ou toxicidade de macro e micronutrientes.

Palavras-chave: Mentha arvensis, Mentha $x$ gracilis, Mentha $x$ piperita var. citrata, hidroponia, nutrição de plantas.

\section{ABSTRACT}

The intention of this study was to determine the levels and accumulation of nutrients in three Mentha species and to test the performance of the nutrient solution for the growth of mint, obtained from previous data of dry matter production and quantity of nutrients extracted by M. arvensis, in NFT (Nutrient Film Technique) hydroponic system. The research was carried out at the Departament of Fitotecny, Universidade Federal de Santa Maria (UFSM), RS, Brazil, from October to December. A completely randomized design was used with three treatments (plant organs) and five replications. Stakes of matrix plants rooted in phenolic foam for 20 days in a nursery, being then transferred to final production gullies. The plants were harvested at 62 (M. arvensis), 69 (M. $x$ gracilis) and 76 (M. x piperita var. citrata) days after planting, separeted in parts (roots, stems, leaves) and dried at $70^{\circ} \mathrm{C}$ for the determination of dry matter and tissue analysis. Nitrogen, calcium and potassium were the macronutrients with larger concentration in all plant parts; the micronutrients were iron, manganese and zinc. There was a higher accumulation of macronutrients in the leaves, followed by stems and roots. It was verified that the nutrient solution elaborated guaranteed a high phytomass production without the plants showing visual symptons of deficiency or toxicity of macro and micronutrients.

Key words: Mentha arvensis, Mentha $x$ gracilis, Mentha $x$ piperita var. citrata, hydroponics, plant nutrition.

\section{INTRODUÇÃO}

O gênero Mentha, família Lamiaceae, compreende aproximadamente 25 espécies originárias do Velho Mundo e adventícias nas Américas (HARLEY \& BRIGTHON, 1977). Algumas foram introduzidas ainda na época do descobrimento do Brasil, enquanto outras vieram com japoneses e europeus no início do século $\mathrm{XX}$. As espécies são valorizadas para uso culinário e para fazer chás medicinais, e são conhecidas principalmente pelo sabor característico e aroma refrescante. Entre as mais populares destacam-se hortelã-

IDepartamento de Ciências Biológicas, Universidade de Cruz Alta (UNICRUZ). Rua Andrade Neves, 308, 98025-810, Cruz Alta, RS, Brasil. E-mail: taneagarlet@hotmail.com.*Autor para correspondência.

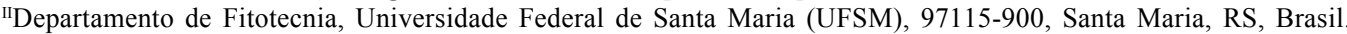


japonesa ou vique (Mentha arvensis L.), hortelã-pimenta (Mentha x piperita var. piperita L.), hortelã-verde ou menta-dos-jardins (Mentha spicata L.), hortelã-rasteira ou hortelã-de-panela (Mentha $x$ villosa Huds.), hortelãlimão (Mentha x piperita var. citrata (Ehrh.) Briq.), menta-do-levante (Mentha x gracilis Sole) e hortelãcomum (Mentha suaveolens Ehrh.).

Os óleos essenciais das mentas são ricos em terpenóides de amplo interesse industrial, para composição de produtos farmacêuticos, alimentícios, cosméticos e aromatizantes do tabaco. A produção mundial estimada desses óleos é de 22.200 toneladas anuais (SANT SANGANERIA, 2005). Índia, China, Brasil, Japão, França e Estados Unidos são os países produtores mundiais do óleo essencial rico em mentol, sendo que a Índia contribui com $70 \%$ do volume desta produção (SRIVASTAVA et al., 2002).

Os nutrientes minerais são fundamentais para o crescimento das plantas e a produção de óleos essenciais em Mentha (BROWN et al., 2003). Esses nutrientes podem ser fornecidos por meio das soluções nutritivas da hidroponia, permitindo rápido crescimento e produção de matéria-prima de qualidade. A técnica do fluxo laminar de nutrientes (NFT) constitui-se em um sistema econômico quanto ao uso da água e dos elementos minerais contidos na solução, desde que haja monitoramento e ajuste da solução nutritiva para o controle de possíveis desordens nutricionais (BACKES et al., 2004). O ambiente protegido possibilita o controle do desenvolvimento das plantas e da solução nutritiva durante o cultivo (SANTOS, 2000). Além disso, a ausência de solo e o cultivo protegido reduzem muito o uso de defensivos agrícolas, oferecendo ao consumidor produtos de melhor qualidade, conferindo vantagens ao uso da hidroponia, especialmente quando se cultivam plantas de emprego farmacêutico.

Poucas informações encontram-se disponíveis na literatura a respeito das exigências nutricionais e da composição mineral de espécies medicinais e, em especial, de mentas (MAIA, 1998a; MAIA, 1998b; RODRIGUES et al., 2004; BLANK et al., 2006). A maior parte dos trabalhos em hidroponia desenvolvidos no Brasil está direcionada à avaliação de teores e necessidades nutricionais de hortaliças folhosas, frutíferas, floríferas e ornamentais (FURLANI et al., 1999). Verifica-se, portanto, a necessidade de estudos que envolvam aspectos nutricionais de plantas aromáticas e medicinais cultivadas em hidroponia, no sistema NFT. Assim, objetivou-se neste trabalho determinar o teor e a acumulação de nutrientes em três espécies de Mentha e testar o desempenho de solução nutritiva calculada para o cultivo de menta no sistema hidropônico NFT.

\section{MATERIAL E MÉTODOS}

O trabalho foi conduzido em casa de vegetação de $250 \mathrm{~m}^{2}$, coberta com polivinilclorídrico (PVC), com $200 \mu \mathrm{m}$ de espessura, na área experimental do Departamento de Fitotecnia, da Universidade Federal de Santa Maria (UFSM), RS, no período de outubro a dezembro de 2004. Realizaram-se três experimentos simultâneos, para as espécies Mentha arvensis L., Mentha $x$ gracilis Sole e Mentha $\mathrm{x}$ piperita var. citrata (Ehrh.) Briq., no delineamento experimental inteiramente casualizado, com três tratamentos (órgãos da planta) e cinco repetições. As mudas das espécies de Mentha oriundas de matrizes cultivadas em solo foram obtidas a partir de estacas caulinares, de $4 \mathrm{~cm}$ de comprimento, com quatro folhas, enraizadas em espuma fenólica com dimensões de $2 \times 2 \times 2 \mathrm{~cm}$, conduzidas em berçário constituído por perfis de polipropileno, com $4 \mathrm{~m}$ de comprimento e $3 \mathrm{~cm}$ de largura, colocados sobre cavaletes com desnível de $2 \%$ para escoamento da solução nutritiva. As mudas permaneceram no berçário até o momento que apresentaram de oito a nove folhas desenvolvidas, aos 20 dias, quando foram transplantadas para as bancadas de produção final constituídas por perfis de polipropileno com $6 \mathrm{~m}$ de comprimento por $10 \mathrm{~cm}$ de largura, sustentados por cavaletes com $0,80 \mathrm{~m}$ de altura e declividade de $2 \%$. O espaçamento foi de $0,25 \mathrm{~m}$ nos perfis e $0,40 \mathrm{~m}$ entre perfis, correspondendo à densidade de 10 plantas $\mathrm{m}^{-2}$ de área ocupada pelo sistema de bancadas. Utilizou-se o sistema NFT, com a solução nutritiva distribuída nos perfis na vazão de $1,8 \mathrm{~L} \mathrm{~s}^{-1}$, por meio de conjunto motobomba de $0,5 \mathrm{HP}$ e recolhida no final da bancada de cultivo por meio de calha coletora, retornando aos reservatórios de fibra de vidro, com capacidade de 500L.

A solução nutritiva foi calculada a partir dos dados de produção de matéria seca e da quantidade de nutrientes extraídos por $\boldsymbol{M}$. arvensis, obtidos por PAULUS et al. (2004). Utilizaram-se as seguintes fontes de nutrientes, com as respectivas quantidades em $\mathrm{g}$ $1000 \mathrm{~L}^{-1}$ de solução nutritiva: nitrato de cálcio $=375$; nitrato de potássio $=737$; monoamônio-fosfato $=134$; sulfato de magnésio $=313$; nitrato de amônio $=146$; nitrato de magnésio $=28$; ácido bórico $=2,86$; sulfato de cobre $=0,08$; sulfato de manganês $=1,54$; sulfato de zinco $=0,22$; molibdato de amônio $=0,024$; e Fe-EDTA $=$ $500 \mathrm{~mL}$ (conforme metodologia descrita por FURLANI \& FURLANI, 1988). Na produção de mudas, essa solução foi diluída a $50 \%$. A solução desenvolvida possui as seguintes doses de íons macronutrientes $(\mathrm{mmol} \mathrm{L}-1): \mathrm{NH}_{4}^{+}=2,95 ; \mathrm{NO}_{3}^{-}=12,15 ; \mathrm{H}_{2} \mathrm{PO}_{4}^{-}=0,98$; 
$\mathrm{K}^{+}=7,08 ; \mathrm{Ca}^{+2}=1,78 ; \mathrm{Mg}^{+2}=1,34 ; \mathrm{SO}_{4}^{-2}=1,27 ;$ e de micronutrientes $\left(\mathrm{mg} \mathrm{L}^{-1}\right): \mathrm{B}=2,884 ; \mathrm{Cu}=0,075 ; \mathrm{Fe}=2,5$; $\mathrm{Mn}=6,084 ; \mathrm{Mo}=0,0883 ; \mathrm{Zn}=0,431$.

A condutividade elétrica (CE) inicial da solução foi $2,38 \mathrm{dS} \mathrm{m}^{-1}$. Realizou-se controle a cada dois dias, com reposição de $50 \%$ dos nutrientes sempre que a $\mathrm{CE}$ atingia $50 \%$ do valor inicial. A renovação da solução nutritiva ocorreu por três vezes, durante o período experimental. Corrigiu-se o $\mathrm{pH}$ a cada dois dias para o valor de $6,0 \pm 0,2$, utilizando-se base $(\mathrm{NaOH}) 0,1$ $\mathrm{M}$ para elevar o $\mathrm{pH}$ ou ácido $\left(\mathrm{H}_{2} \mathrm{SO}_{4}\right)$, $1 \mathrm{M}$ para diminuir o pH, após completar o volume dos reservatórios com água. Controlou-se a circulação das soluções por meio de temporizador programado para acionar a motobomba durante 15 minutos, com intervalos de 15 minutos, no período diurno ( $7 \mathrm{~h}-20 \mathrm{~h})$, e 15 minutos a cada intervalo de $2 \mathrm{~h}$, durante o período noturno (20h$7 \mathrm{~h})$.

As plantas foram colhidas aos 62 ( $\boldsymbol{M}$. arvensis ), 69 (M. x gracilis) e 76 dias após o plantio das estacas (M. x piperita var. citrata), no início da floração, exceto $M$. x piperita var. citrata, que floresceu apenas em março de 2005, conforme observado em cultivo a campo. As plantas foram separadas em raízes, hastes e folhas, secas em estufa a $70^{\circ} \mathrm{C}$, até massa constante, para determinação de matéria seca e análise de tecidos.

Os teores de macro e micronutrientes na matéria seca das raízes, hastes e folhas foram determinados no Laboratório de Ecologia Florestal da UFSM e extraídos da seguinte forma: $\mathrm{N}$, por digestão sulfúrica; $\mathrm{P}, \mathrm{K}, \mathrm{Ca}, \mathrm{Mg}, \mathrm{S}, \mathrm{Cu}, \mathrm{Fe}, \mathrm{Mn}$ e Zn, por digestão nítrica-perclórica e $\mathrm{B}$, por digestão seca por meio de incineração em forno mufla. A determinação seguiu o método de Kjeldahl para N; espectrometria visível para $\mathrm{P}$ e B; fotometria de chama para $\mathrm{K}$; turbidimetria para $\mathrm{S}$ e espectrofotometria de absorção atômica para $\mathrm{Ca}, \mathrm{Mg}$, $\mathrm{Cu}, \mathrm{Fe}, \mathrm{Mn}$ e Zn (TEDESCO et al., 1995; MIYAZAWA et al, 1999). Os resultados obtidos foram submetidos à análise de variância e as médias comparadas pelo teste de Tukey a 5\% de probabilidade de erro.

\section{RESULTADOS E DISCUSSÃO}

O teor de nutrientes das três espécies de Mentha, nas diversas partes das plantas, pode ser observado na tabela 1 . Nitrogênio, cálcio e potássio foram os macronutrientes com maior concentração em todas as partes das plantas de Mentha, concordando com dados de MALAVOLTA (2006), para as principais culturas brasileiras de interesse econômico. Já os micronutrientes de maior teor foram ferro, manganês e zinco.
O nitrogênio foi o macronutriente encontrado em maior teor nas folhas e raízes das três espécies, enquanto que nas hastes de $\boldsymbol{M}$. arvensis e M. x piperita var. citrata foi o cálcio e nas hastes de M. x gracilis foi o potássio. O nitrogênio é, geralmente, o nutriente mais exigido pelas culturas, já que atua como componente estrutural nas moléculas de aminoácidos e proteínas, e estimula o crescimento vegetativo, a formação e o desenvolvimento de gemas floríferas (MARSCHNER, 1995). Em casos de baixo suprimento de nitrogênio ocorre redução na produção de folhas, pois as folhas apresentam assimilação do nitrato em proteína (MAFFEIS et al., 2000). O papel do cálcio é participar na síntese da parede celular, divisão e elongação celular (TAIZ \& ZEIGER, 2004), proporcionando rigidez e estrutura às membranas celulares. Já o potássio auxilia na translocação de fotossintatos para partes em crescimento e na extensão celular (MARSCHNER, 1995).

Os teores de ferro nas raízes são os que mais se destacam quando comparados aos teores das folhas. Os teores do nutriente nas raízes foram maiores de 40 a 50 vezes aos teores das folhas. BORKERT et al. (2001) comentam que faixas de concentração de ferro são bastante variáveis e grande número de plantas pode ser enquadrado dentro de valores entre 50 e $250 \mathrm{mg}$ $\mathrm{kg}^{-1}$, como suficientes para boa nutrição. Já valores acima de $1000 \mathrm{mg} \mathrm{kg}^{-1}$ geralmente estão associados à toxicidade. Embora abundante, o ferro pode se tornar insolúvel, ao se combinar com oxigênio e formar oxihidratos (SCHMIDT, 2003), que podem ficar adsorvidos no apoplasto das células radiculares, não ocasionando sintomas de toxicidade que seriam esperados se houvesse absorção em excesso. Não foram observados sintomas visuais de deficiência ou toxicidade, podendo-se considerar que os nutrientes fornecidos pela solução hidropônica foram adequados ao crescimento das plantas, o que pode ser confirmado pela alta produção de matéria seca.

A amplitude de variação nos teores foliares dos nutrientes (Tabela 1), em função das espécies de Mentha, corresponde a macronutrientes $\left(\mathrm{g} \mathrm{kg}^{-1}\right)$ : $\mathrm{N}=$ 39,69 a 43,$43 ; \mathrm{P}=5,22$ a 6,$15 ; \mathrm{K}=11,87$ a 15,$95 ; \mathrm{Ca}=13,48$ a 20,$45 ; \mathrm{Mg}=6,95$ a 10,$35 ; \mathrm{S}=5,50$ a 7,50 ; e micronutrientes $\left(\mathrm{mg} \mathrm{kg}^{-1}\right)$ : $\mathrm{B}=39,03$ a 50,21; $\mathrm{Cu}=17,37 \mathrm{a}$ 28,99; $\mathrm{Fe}=307,60$ a 352,00; $\mathrm{Mn}=133,27$ a 203,20; $\mathrm{Zn}=$ 59,61 a 72,25. Nos teores da parte aérea, seguindo a proporção de matéria seca entre hastes e folhas, a amplitude foi: $\mathrm{N}=26,52$ a 29,$68 ; \mathrm{P}=4,18$ a 5,$71 ; \mathrm{K}=14,64$ a 16,$74 ; \mathrm{Ca}=14,87$ a 18,$72 ; \mathrm{Mg}=5,85$ a 7,$49 ; \mathrm{S}=2,66$ a 4,$25 ; \mathrm{B}=29,79$ a 38,$56 ; \mathrm{Cu}=18,67$ a 24,$38 ; \mathrm{Fe}=233,95 \mathrm{a}$ 278,$28 ; \mathrm{Mn}=194,32$ a 266,14 e $\mathrm{Zn}=61,97$ a 70,06 . 
Tabela 1 - Teor de macronutrientes $\left(\mathrm{g} \mathrm{kg}^{-1}\right)$ e micronutrientes $\left(\mathrm{mg} \mathrm{kg}^{-1}\right)$ nas folhas, hastes, raízes e média de parte aérea (PA) das plantas de Mentha arvensis L., Mentha x gracilis Sole e Mentha x piperita var. citrata (Ehrh.) Briq. em cultivo hidropônico - NFT, UFSM, Santa Maria, RS, 2004

\begin{tabular}{|c|c|c|c|c|c|c|c|c|c|c|c|}
\hline Partes da planta & $\mathrm{N}$ & $\mathrm{P}$ & $\mathrm{K}$ & $\mathrm{Ca}$ & $\mathrm{Mg}$ & $\mathrm{S}$ & $\mathrm{B}$ & $\mathrm{Cu}$ & $\mathrm{Fe}$ & $\mathrm{Mn}$ & $\mathrm{Zn}$ \\
\hline \multicolumn{12}{|c|}{ 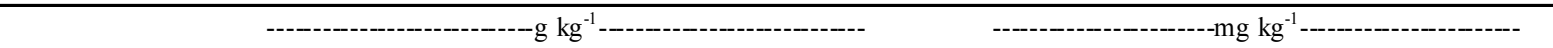 } \\
\hline \multicolumn{12}{|c|}{ Mentha arvens is L. } \\
\hline Folhas & $43,43 \mathrm{a}$ & $5,22 b$ & $11,87 \mathrm{~b}$ & $20,45 \mathrm{a}$ & $10,35 \mathrm{a}$ & $5,78 \mathrm{a}$ & $41,94 \mathrm{a}$ & $28,99 b$ & $347,27 b$ & $203,20 \mathrm{a}$ & $72,25 b$ \\
\hline Hastes & $14,17 \mathrm{c}$ & $3,41 \mathrm{c}$ & $16,68 \mathrm{a}$ & $17,45 \mathrm{a}$ & $5,39 b$ & $0,36 \mathrm{c}$ & $20,86 b$ & $21,00 \mathrm{~b}$ & $150,67 \mathrm{~b}$ & $246,07 \mathrm{a}$ & $54,40 \mathrm{~b}$ \\
\hline Raízes & $33,16 b$ & $7,81 \mathrm{a}$ & $17,79 \mathrm{a}$ & $14,73 b$ & $5,87 \mathrm{~b}$ & $2,03 b$ & $42,98 \mathrm{a}$ & $117,53 \mathrm{a}$ & $14186,67 \mathrm{a}$ & $199,20 \mathrm{a}$ & $133,33 a$ \\
\hline Média (PA) & 26,54 & 4,18 & 14,64 & 18,72 & 7,49 & 2,66 & 29,79 & 24,38 & 233,95 & 227,91 & 61,97 \\
\hline $\mathrm{CV}(\%)$ & 7,11 & 5,06 & 3,80 & 7,38 & 10,83 & 18,30 & 12,81 & 34,36 & 18,60 & 10,90 & 12,51 \\
\hline DMS (5\%) & 5,38 & 0,69 & 1,47 & 3,25 & 1,95 & 1,24 & 11,32 & 48,07 & 2281,72 & 59,03 & 27,16 \\
\hline \multicolumn{12}{|c|}{ Mentha x gracilis Sole } \\
\hline Folhas & $41,40 \mathrm{a}$ & $6,01 \mathrm{~b}$ & $15,95 \mathrm{a}$ & $13,48 \mathrm{a}$ & $6,97 \mathrm{a}$ & $5,50 \mathrm{a}$ & $39,03 \mathrm{a}$ & $24,59 b$ & $352,00 \mathrm{~b}$ & $133,27 b$ & $64,93 b$ \\
\hline Hastes & $14,69 b$ & $4,66 \mathrm{c}$ & $17,75 a$ & $16,66 a$ & $5,05 \mathrm{~b}$ & $0,45 \mathrm{c}$ & $24,55 b$ & $14,73 b$ & $184,00 \mathrm{~b}$ & $272,40 \mathrm{a}$ & $67,67 b$ \\
\hline Raízes & $37,29 a$ & $8,08 \mathrm{a}$ & $15,38 \mathrm{a}$ & $18,17 \mathrm{a}$ & $6,34 \mathrm{a}$ & $2,93 b$ & $41,89 \mathrm{a}$ & $120,53 \mathrm{a}$ & $13076,67 \mathrm{a}$ & $143,73 b$ & $138,13 a$ \\
\hline Média (PA) & 29,68 & 5,41 & 16,74 & 14,87 & 6,13 & 3,29 & 32,67 & 20,26 & 278,28 & 194,32 & 66,13 \\
\hline CV $(\%)$ & 6,21 & 3,82 & 7,36 & 12,76 & 7,35 & 15,43 & 14,44 & 36,09 & 6,64 & 13,85 & 5,69 \\
\hline DMS (5\%) & 4,84 & 0,60 & 3,02 & 5,15 & 1,13 & 1,15 & 12,72 & 48,18 & 755,43 & 63,56 & 12,86 \\
\hline \multicolumn{12}{|c|}{ Mentha x piperita var. citrata (Ehrh.) Briq. } \\
\hline Folhas & $39,69 a$ & $6,15 b$ & $14,59 \mathrm{a}$ & $14,59 \mathrm{~b}$ & $6,95 \mathrm{a}$ & $7,50 \mathrm{a}$ & $50,21 \mathrm{a}$ & $17,37 b$ & $307,60 \mathrm{~b}$ & $167,80 \mathrm{~b}$ & $59,61 \mathrm{~b}$ \\
\hline Hastes & $14,51 \mathrm{~b}$ & $5,32 \mathrm{~b}$ & $15,57 \mathrm{a}$ & $18,39 \mathrm{ab}$ & $4,86 \mathrm{~b}$ & $1,28 b$ & $27,93 b$ & $19,87 b$ & $190,60 \mathrm{~b}$ & $355,80 \mathrm{a}$ & $79,59 \mathrm{~b}$ \\
\hline Raízes & $37,92 \mathrm{a}$ & $14,43 \mathrm{a}$ & $12,16 \mathrm{~b}$ & $24,63 \mathrm{a}$ & $7,42 \mathrm{a}$ & $1,80 \mathrm{~b}$ & $33,42 b$ & $131,40 \mathrm{a}$ & $15799,33 \mathrm{a}$ & $251,00 \mathrm{ab}$ & $155,60 \mathrm{a}$ \\
\hline Média (PA) & 26,52 & 5,71 & 15,10 & 16,58 & 5,85 & 4,25 & 38,56 & 18,67 & 246,39 & 266,14 & 70,06 \\
\hline CV $(\%)$ & 3,80 & 24,42 & 6,36 & 16,64 & 6,07 & 13,26 & 13,57 & 37,74 & 24,97 & 25,66 & 21,74 \\
\hline DMS (5\%) & 2,92 & 5,28 & 2,25 & 8,01 & 0,97 & 1,17 & 12,65 & 53,15 & 3398,81 & 166,00 & 53,52 \\
\hline
\end{tabular}

Médias não seguidas de mesma letra nas colunas diferem entre si pelo teste de Tukey em nível de 5\% de probabilidade de erro.

Ao cultivar plantas de M. arvensis em vasos contendo sílica e solução nutritiva descrita por Sarruge, MAIA (1998a) obteve teores foliares de macronutrientes $\left(\mathrm{g} \mathrm{kg}^{-1}\right)$ : $\mathrm{N}=44,30 ; \mathrm{P}=3,70 ; \mathrm{K}=42,10 ; \mathrm{Ca}=14,90 ; \mathrm{Mg}=$ 6,70; $\mathrm{S}=1,90 ;$ e de micronutrientes $\left(\mathrm{mg} \mathrm{kg}^{-1}\right): \mathrm{B}=51,00$; $\mathrm{Cu}=9,00 ; \mathrm{Fe}=432,00 ; \mathrm{Mn}=56,00 \mathrm{e} \mathrm{Zn}=46,00$. Em outro experimento também com $\boldsymbol{M}$. arvensis, MAIA (1998b) encontrou na parte aérea, teores de $\mathrm{N}=10,88 ; \mathrm{P}=1,26$; $\mathrm{K}=9,89 ; \mathrm{Ca}=9,05 ; \mathrm{Mg}=2,27 ; \mathrm{S}=3,01 ; \mathrm{B}=22,00 ; \mathrm{Cu}=$ 20,$58 ; \mathrm{Fe}=158,50 ; \mathrm{Mn}=21,00 \mathrm{e} \mathrm{Zn}=38,85$. Ao fazer uma comparação com os resultados do presente estudo, verifica-se que os teores foliares obtidos por MAIA (1998a) de: N, Ca, Mg e B apresentaram valores semelhantes; P, S, Cu, Mn e Zn mostraram-se inferiores; $\mathrm{K}$ e Fe foram superiores ao deste estudo. Para a parte aérea das espécies de Mentha, os teores de nutrientes foram bem superiores aos encontrados por MAIA (1998b), sendo que apenas teores de enxofre e cobre apresentaram valores semelhantes.

Essas variações encontradas nos teores de nutrientes podem ser explicadas, segundo MALAVOLTA (2006), pela influência de fatores externos e internos que interferem na absorção iônica. $\mathrm{O}$ abaixamento da tensão de oxigênio na solução e da temperatura diminui a absorção de nutrientes, o que acarreta menor concentração no suco celular. Oxigênio dissolvido e calor (com temperatura ótima em torno de $30^{\circ} \mathrm{C}$ ) são necessários para que se processe a respiração, fonte de ATP para a absorção ativa. Espécies e variedades apresentam capacidades diferentes para absorver tanto macro quanto micronutrientes, o que pode estar relacionado com parâmetros cinéticos (concentração e velocidade de absorção). O processo de absorção está sob controle genético, sendo que há genes que se expressam mais ou menos, o que varia a absorção. A concentração externa de cátions e de ânions, o pH, a intensidade transpiratória, a morfologia e o tamanho das raízes, além do nível de carboidratos e de sais presentes no protoplasto, constituem também fatores que influenciam a absorção.

No sistema NFT, o volume da solução nutritiva por planta cultivada não deve ser inferior a 1 $\mathrm{L}$, pois quanto maior o volume por planta, menores alterações nas concentrações de nutrientes ocorrerão 
na solução nutritiva (FURLANI et al., 1995). No presente trabalho, o volume da solução no reservatório foi de 4L planta $^{-1}$, sendo que a água evapotranspirada foi reposta diariamente. As plantas têm grande capacidade de adaptação às diferentes condições nutritivas. No entanto, o mau uso destas pode acarretar sérios prejuízos (MARTINEZ \& SILVA FILHO, 2004). Um adequado fornecimento de nutrientes está diretamente relacionado ao volume de solução, ao estádio de desenvolvimento, à taxa de absorção de nutrientes e freqüência de renovação e à reposição de nutrientes na solução nutritiva (HOAGLAND \& ARNON, 1950).

Analisando o total de nutrientes fornecidos pela solução hidropônica utilizada, constatou-se que os valores estão adequados em relação aos referidos por BARRY (1996), citado por FURLANI et al. (1999), com as seguintes faixas $\left(\mathrm{mg} \mathrm{L}^{-1}\right)$ : N (70-250), P (15-80), $\mathrm{K}(150-400), \mathrm{Ca}(70-200), \mathrm{Mg}(15-80), \mathrm{S}(20-200), \mathrm{Fe}(0,8-$ 6), $\mathrm{Mn}(0,5-2), \mathrm{B}(0,1-0,6), \mathrm{Cu}(0,05-0,3), \mathrm{Zn}(0,1-0,5) \mathrm{e}$ Mo $(0,05-0,15)$.

Quando se procede a análise das exigências nutricionais de plantas, visando ao cultivo em solução nutritiva, segundo FURLANI et al. (1999), deve-se enfocar as relações entre os nutrientes, pois essa é uma indicação da relação de extração do meio de crescimento. As relações entre os teores foliares de potássio e os demais macronutrientes $\left(\mathrm{g} \mathrm{kg}^{-1}\right)$ para $\boldsymbol{M}$. arvensis, $M$. x gracilis e $M$. x piperita var. citrata foram, respectivamente, $\mathrm{K}: \mathrm{N}(1: 3,66 ; 1: 2,60 ; 1: 2,72), \mathrm{K}: \mathrm{P}(1: 0,44$; $1: 0,38 ; 1: 0,42), \mathrm{K}: \mathrm{Ca}(1: 1,72 ; 1: 0,85 ; 1: 1), \mathrm{K}: \mathrm{Mg}(1: 0,87$; 1:0,44; 1:0,48) e K:S (1:0,49; 1:0,34; 1:0,51). Essas relações foram superiores àquelas encontradas por MAIA (1998a) e MAIA (1998b), em hidroponia com substrato do tipo sílica, e por BLANK et al. (2006) em solo. Verificou-se que as plantas de $\boldsymbol{M}$. arvensis absorvem maior quantidade de nitrogênio, cálcio e magnésio para cada unidade de potássio absorvido do que as outras duas espécies. No entanto, fósforo e enxofre apresentaram relações semelhantes para as três espécies.

As relações entre os teores de potássio e os demais macronutrientes devem ser consideradas com cautela, havendo necessidade de outros estudos a fim de se definir padrões de relações entre macronutrientes em Mentha, visando à manutenção do equilíbrio eletroquímico da solução, já que é grande a variação nas concentrações encontradas em outros experimentos (MAIA, 1998a; MAIA, 1998b; BLANK et al., 2006).

$\mathrm{Na}$ tabela 2, observam-se diferenças significativas na produção de matéria seca e, conseqüentemente, nas quantidades de nutrientes extraídas pelas raízes e parte aérea das espécies de
Mentha. FURLANI et al. (1999), em estudos com plantas de alface, verificaram que as variações são devidas às cultivares e também à idade de colheita das plantas. GUPTA (2001) cita que quanto maior a capacidade da planta em acumular um nutriente maior será a diferença na concentração desse nutriente, em resposta a taxas variáveis de adubação. Então, o conhecimento sobre as partes das plantas que mais acumulam nutrientes deve se destacar como um critério para delimitar os níveis de nutrientes, da suficiência à toxicidade.

No caso das Mentha, verifica-se que houve maior acúmulo de macronutrientes nas folhas, depois nas hastes e por último nas raízes. Nitrogênio, cálcio e potássio foram os nutrientes extraídos em maior quantidade na planta inteira. Para os micronutrientes, foram ferro, manganês e zinco. A extração dos nutrientes é indicada pela seguinte ordem decrescente: $\mathrm{N}>\mathrm{Ca}>\mathrm{K}>\mathrm{Mg}>\mathrm{P}>\mathrm{S}>\mathrm{Fe}>\mathrm{Mn}>\mathrm{Zn}>\mathrm{Cu}>\mathrm{B}$ para $\boldsymbol{M}$. arvensis, $\mathrm{N}>\mathrm{K}>\mathrm{Ca}>\mathrm{Mg}>\mathrm{P}>\mathrm{S}>\mathrm{Fe}>\mathrm{Mn}>\mathrm{Zn}>\mathrm{B}>\mathrm{Cu}$ para M. $x$ gracilis e $\mathrm{N}>\mathrm{Ca}>\mathrm{K}>\mathrm{P}>\mathrm{Mg}>\mathrm{S}>\mathrm{Fe}>\mathrm{Mn}>\mathrm{Zn}>\mathrm{B}>\mathrm{Cu}$ para $M$. x piperita var. citrata. Os resultados obtidos para esta última espécie foram semelhantes aos encontrados por RODRIGUES et al. (2004), referindose que plantas de $\boldsymbol{M}$. x piperita absorvem mais fósforo que magnésio no período de florescimento. No presente estudo, M. x piperita var. citrata absorveu mais fósforo, porém não floresceu durante a condução do experimento. No entanto, as outras duas espécies acumularam mais magnésio que fósforo e floresceram. Esse desempenho diferenciado pode ser devido à ampla variabilidade genotípica que é encontrada no gênero Mentha(HARLEY \& BRIGTHON, 1977).

Considerando a quantidade de nutrientes extraídos pela planta inteira (mg planta $\left.{ }^{-1}\right)$, em espécies de Mentha (Tabela 2), verifica-se que os valores foram superiores para todos os nutrientes quando comparados aos encontrados por MAIA (1998a) e MAIA (1998b). Os valores de matéria seca total obtidos por esses autores foram, respectivamente, $32,10 \mathrm{~g}$ e $89,44 \mathrm{~g}$. No presente trabalho, destaca-se o alto rendimento de matéria seca total de 98,43 a $142,66 \mathrm{~g}$ planta $^{-1}$, indicando um ótimo crescimento das espécies no sistema NFT.

\section{CONCLUSÃO}

Nitrogênio, cálcio e potássio são os macronutrientes de maior concentração em todas as partes das plantas de Mentha arvensis, Mentha x gracilis e Mentha x piperita var. citrata; os micronutrientes são ferro, manganês e zinco. Ocorre maior acúmulo de macronutrientes nas folhas, seguidas 
Tabela 2 - Produção de matéria seca $\left(\mathrm{g}_{\text {planta }}{ }^{-1}\right)$ e quantidade de nutrientes extraídos pelas folhas, hastes, raízes e planta inteira (PI) de Mentha arvensis L., Mentha x gracilis Sole e Mentha x piperita var. citrata (Ehrh.) Briq. em cultivo hidropônico - NFT, UFSM, Santa Maria, RS, 2004.

\begin{tabular}{|c|c|c|c|c|c|c|c|c|c|c|c|c|}
\hline $\begin{array}{l}\text { Partes da } \\
\text { planta }\end{array}$ & $\begin{array}{c}\text { Matéria } \\
\text { seca }\end{array}$ & $\mathrm{N}$ & $\mathrm{P}$ & $\mathrm{K}$ & $\mathrm{Ca}$ & $\mathrm{Mg}$ & $\mathrm{S}$ & $\mathrm{B}$ & $\mathrm{Cu}$ & $\mathrm{Fe}$ & $\mathrm{Mn}$ & $\mathrm{Zn}$ \\
\hline \multicolumn{13}{|c|}{ - } \\
\hline \multicolumn{13}{|c|}{ Mentha arvensis L. } \\
\hline Folhas & $38,38 b$ & $1666,84 \mathrm{a}$ & $200,34 a$ & $455,57 \mathrm{~b}$ & $785,00 \mathrm{~b}$ & $397,36 a$ & $221,71 \mathrm{a}$ & $1,61 \mathrm{a}$ & $1,11 \mathrm{a}$ & $13,33 b$ & $7,80 \mathrm{~b}$ & $2,77 \mathrm{a}$ \\
\hline Hastes & $52,22 \mathrm{a}$ & $739,78 b$ & $178,10 \mathrm{~b}$ & $870,85 \mathrm{a}$ & $911,06 \mathrm{a}$ & $281,28 b$ & $18,62 b$ & $1,09 \mathrm{~b}$ & $1,10 \mathrm{a}$ & $7,87 b$ & $12,85 \mathrm{a}$ & $2,84 a$ \\
\hline Raízes & $7,83 \mathrm{c}$ & $259,62 \mathrm{c}$ & $61,18 \mathrm{c}$ & $139,32 \mathrm{c}$ & $115,31 \mathrm{c}$ & $45,99 \mathrm{c}$ & $15,87 \mathrm{~b}$ & $0,34 \mathrm{c}$ & $0,92 \mathrm{a}$ & $111,08 \mathrm{a}$ & $1,56 \mathrm{c}$ & $1,04 b$ \\
\hline PI & 98,43 & 2666,24 & 439,62 & 1465,74 & 1811,37 & 724,63 & 256,20 & 3,04 & 3,13 & 132,28 & 22,21 & 6,65 \\
\hline $\mathrm{CV}(\%)$ & 9,63 & 9,22 & 5,18 & 2,37 & 6,82 & 9,17 & 11,67 & 18,60 & 15,15 & 16,60 & 13,40 & 5,30 \\
\hline DMS (5\%) & 5,32 & 205,42 & 19,00 & 29,00 & 103,17 & 55,50 & 24,98 & 0,47 & 0,39 & 18,34 & 2,48 & 0,29 \\
\hline \multicolumn{13}{|c|}{ Mentha x gracilis Sole } \\
\hline Folhas & $74,95 \mathrm{a}$ & $3103,18 a$ & $449,70 \mathrm{a}$ & $1195,70 \mathrm{a}$ & $1010,33 a$ & $522,15 \mathrm{a}$ & $412,22 \mathrm{a}$ & $2,92 \mathrm{a}$ & $1,84 \mathrm{a}$ & $26,38 b$ & $9,99 \mathrm{~b}$ & $4,87 \mathrm{a}$ \\
\hline Hastes & $58,60 \mathrm{a}$ & $860,83 \mathrm{~b}$ & $272,88 b$ & $1039,95 \mathrm{~b}$ & $976,28 \mathrm{a}$ & $295,73 b$ & $26,56 b$ & $1,44 b$ & $0,86 \mathrm{~b}$ & $10,78 \mathrm{c}$ & $15,96 \mathrm{a}$ & $3,96 b$ \\
\hline Raízes & $9,11 \mathrm{~b}$ & $339,74 \mathrm{c}$ & $73,61 \mathrm{c}$ & $140,08 \mathrm{c}$ & $165,56 \mathrm{~b}$ & $57,76 \mathrm{c}$ & $26,69 b$ & $0,38 \mathrm{c}$ & $1,10 \mathrm{~b}$ & $119,13 \mathrm{a}$ & $1,31 \mathrm{c}$ & $1,26 \mathrm{c}$ \\
\hline PI & 142,66 & 4303,75 & 796,19 & 2375,73 & 2152,17 & 875,64 & 465,47 & 4,74 & 3,80 & 156,29 & 27,26 & 10,09 \\
\hline $\mathrm{CV}(\%)$ & 19,11 & 4,580 & 1,87 & 6,12 & 9,76 & 7,89 & 17,24 & 16,08 & 17,69 & 7,94 & 13,31 & 5,58 \\
\hline DMS (5\%) & 15,32 & 164,7 & 12,45 & 121,42 & 175,52 & 57,74 & 67,01 & 0,64 & 0,56 & 10,36 & 3,03 & 0,47 \\
\hline \multicolumn{13}{|c|}{ Mentha x piperita var. citrata (Ehrh.) Briq. } \\
\hline Folhas & $60,41 \mathrm{a}$ & $2397,87 \mathrm{a}$ & $371,52 \mathrm{a}$ & $881,38 b$ & $881,18 b$ & $419,65 \mathrm{a}$ & $452,87 \mathrm{a}$ & $3,03 \mathrm{a}$ & $1,05 \mathrm{~b}$ & $18,58 b$ & $10,14 b$ & $3,60 \mathrm{~b}$ \\
\hline Hastes & $66,26 a$ & $961,43 b$ & $352,50 \mathrm{a}$ & $1031,89 \mathrm{a}$ & $1218,30 \mathrm{a}$ & $322,02 b$ & $85,03 b$ & $1,85 \mathrm{~b}$ & $1,32 \mathrm{ab}$ & $12,63 b$ & $23,57 \mathrm{a}$ & $5,27 \mathrm{a}$ \\
\hline Raízes & $14,23 b$ & $539,60 \mathrm{c}$ & $205,39 b$ & $172,99 \mathrm{c}$ & $350,53 \mathrm{c}$ & $105,59 \mathrm{c}$ & $25,66 \mathrm{c}$ & $0,47 \mathrm{c}$ & $1,87 \mathrm{a}$ & $224,82 \mathrm{a}$ & $3,57 \mathrm{~b}$ & $2,21 \mathrm{c}$ \\
\hline PI & 140,90 & 3898,90 & 929,41 & 2086,26 & 2450,21 & 847,26 & 563,56 & 5,35 & 4,24 & 256,03 & 37,28 & 11,08 \\
\hline CV(\%) & 13,38 & 4,75 & 10,55 & 5,82 & 10,48 & 8,28 & 5,75 & 16,96 & 22,85 & 23,32 & 25,86 & 8,57 \\
\hline DMS (5\%) & 10,60 & 154,61 & 81,91 & 101,34 & 214,48 & 58,59 & 27,06 & 0,76 & 0,81 & 49,87 & 8,05 & 0,79 \\
\hline
\end{tabular}

Médias não seguidas de mesma letra nas colunas diferem entre si pelo teste de Tukey em nível de 5\% de probabilidade de erro.

pelas hastes e raízes. Para o cultivo das três espécies de Mentha, no sistema hidropônico NFT, a solução nutritiva elaborada garante elevada produção de fitomassa, sem que as plantas apresentem sintomas visuais de deficiência ou toxicidade de nutrientes.

\section{REFERÊNCIAS}

BACKES, F.A.A.L. et al. Reposição de nutrientes em solução nutritiva para o cultivo hidropônico de alface. Ciência Rural, v.34, p.1407-1414, 2004.

BLANK, A.F. et al. Efeitos da adubação química e da calagem na nutrição de melissa e hortelã-pimenta. Horticultura Brasileira, v.24, n.2, p.195-198, 2006.

BORKERT, C.M. et al. Disponibilidade e avaliação de elementos catiônicos: ferro e manganês. In: FERREIRA, M.E. (Org.). Micronutrientes e elementos tóxicos na agricultura. Jaboticabal: CNPq/ FAPESP/ POTAFOS, 2001. p.151-186.

BROWN, B. et al. The critical role of nutrient management in mint production. Better Crops, v.87, n.4, p.9-11, 2003

FURLANI, A.M.C.; FURLANI, P.R. Composição e pH de soluções nutritivas para estudos fisiológicos e seleção de plantas em condições nutricionais adversas. Campinas: Instituto Agronômico, 1988. 34p.

FURLANI, P.R. Cultivo de alface pela técnica de hidroponia - NFT. Campinas: Instituto Agronômico, 1995. 18p. (Documentos IAC, 55).

FURLANI, P.R. et al. Cultivo hidropônico de plantas. Campinas: Instituto Agronômico, 1999. 52p. (Boletim Técnico, 180).

GUPTA, U.C. Micronutrientes e elementos tóxicos em plantas e animais. In: FERREIRA, M.E. (Org.). Micronutrientes e elementos tóxicos na agricultura. Jaboticabal: POTAFOS, 2001. p.13-42.

HARLEY, R.M.; BRIGHTON, C.A. Chromosome numbers in the genus Mentha L. Botanical Journal of the Linnean Society, v.74, p.71-96, 1977.

HOAGLAND, D.R.; ARNON, D.L. The water culture methods for growing plants without soil. Berkeley: University of California, 1950. 32p. (Circular, 347).

MAFFEIS, A.R. et al. Reflexos das deficiências de macronutrientes e boro no crescimento de plantas, produção e qualidade de óleo essencial em Eucalyptus citriodora. Scientia Florestalis, n.57, p.87-98, 2000. 
MAIA, N.B. Efeito da nutrição mineral na qualidade do óleo essencial da menta (Mentha arvensis L.) cultivada em solução nutritiva. In: MING, L.C. Plantas medicinais, aromáticas e condimentares: avanços na pesquisa agronômica. Botucatu: UNESP, 1998a. p.81-95.

MAIA, N.B. Produção e qualidade do óleo essencial de duas espécies de menta cultivadas em soluções nutritivas. Piracicaba. 1998b. 105f. Tese (Doutorado em Agronomia) - Escola Superior de Agricultura "Luiz de Queiroz", Universidade de São Paulo.

MALAVOLTA, E. Manual de nutrição mineral de plantas São Paulo: Ceres, 2006. 638p.

MARSCHNER, H. Mineral nutrition of higher plants. 2.ed. San Diego: Academic, 1995. 888p.

MARTINEZ, H.E.P.; SILVA FILHO, J.B. Introdução ao cultivo hidropônico de plantas. 2.ed. Viçosa: UFV, 2004 $111 \mathrm{p}$.

MIYAZAWA, M. et al. Análises químicas de tecido vegetal. In: SILVA, F.C. (Org.). Manual de análises químicas de solos, plantas e fertilizantes. Brasília: EMBRAPA, 1999. p.171-223.

PAULUS, D. et al. Rendimento de biomassa e óleo essencial de menta japonesa (Mentha arvensis L.). Revista Brasileira de Plantas Medicinais, v.7, n.1, p.34-42, 2004.
RODRIGUES, C.R. et al. Nutrição mineral, crescimento e teor de óleo essencial da menta em solução nutritiva sob diferentes concentrações de fósforo e épocas de coleta. Horticultura Brasileira, v.22, n.3, p.576-578, 2004.

SANT SANGANERIA. Vibrant India. Opportunities for the flavor and fragrance industry. Perfumer and flavorist, v.30, p.24-34, 2005.

SANTOS, O.S. (Ed.). Hidroponia da alface. Santa Maria: UFSM/Pró-Reitoria de Extensão, 2000. 160p.

SCHMIDT, W. Iron solutions: acquisition strategies and signaling parthways in plants. Trends in Plant Science, v.8, n.4, 188$193,2003$.

SRIVASTAVA, R.K. et al. Characteristics of menthol mint Mentha arvensis cultivated on industrial scale in the IndoGangetic plains. Industrial Crops and Products, v.15, p.189198,2002

TAIZ, L.; ZEIGER, E. Fisiologia vegetal. 3.ed. Porto Alegre: Artmed, 2004. 719p.

TEDESCO, M.J. et al. Análise de solo, plantas e outros materiais. 2.ed. Porto Alegre: UFRGS, 1995. 144p. (Boletim Técnico, 5). 